\title{
Life Expectancy of an Individual
}

National Cancer Institute

\section{Source}

National Cancer Institute. Life Expectancy of an Individual. NCI Thesaurus. Code C99547.

The estimate of the future survival of a subject. 